\title{
Why menthol bans protect African Americans
}

\author{
Kelsey Romeo-Stuppy', Laurent Huber', Natasha Phelps², Delmonte Jefferson ${ }^{3}$, Carol McGruder ${ }^{4}$
}

In 2020, the African American Tobacco Control Leadership Council (AATCLC), Action on Smoking and Health (ASH), the American Medical Association (AMA), and the National Medical Association (NMA), sued the U.S. Food and Drug Administration (FDA) for its inaction on menthol cigarettes ${ }^{1}$. In April 2021, the FDA responded to the lawsuit and the citizen's petition (2013) that preceded it, stating its intention to begin rulemaking to ban menthol as a characterizing flavor in cigarettes, an authority the agency has had since $2009^{2}$.

Menthol is a health equity issue in the United States. Tobacco use is a major contributor to the top causes of death/disease among African Americans (heart disease, cancer, stroke), and approximately 40000 African Americans die from tobacco-related cancers each year. Almost 9 out of 10 African Americans who smoke use menthol cigarettes, compared to less than $30 \%$ of Whites who smoke ${ }^{3}$. This 'brand choice' is not a coincidence. For decades, the tobacco industry perniciously targeted Black communities with menthol for tremendous profit, researching and appropriating Black culture along the way. From free menthol giveaways in ice cream truck-like vans in the 1960s-1990s to saturating urban Black neighborhoods with menthol advertisements, cheap prices, and coupons through today, the industry has flooded and continues to target Black communities with this minty poison ${ }^{4}$.

A ban on the manufacturing and distribution of menthol cigarettes by the FDA would begin to address the health inequities caused by the industry's targeting and the FDA's failure to add menthol to the list of already-banned flavors in cigarettes. In the meantime, state and local governments have taken action to prohibit the retail sale of flavored tobacco products, including menthol cigarettes. These policies are a big step forward for health equity and social justice in the United States. However, the industry has fueled misinformation related to these policies. As a result, there has been some mixed reaction to this progress. Some have alleged that a menthol ban targets the 'choice' of Black Americans who smoke and could lead to increased police interaction, even though these policies regulate retailers and others in the industry ${ }^{5}$. The tobacco industry misinformation supports this claim. This is a tobacco industry tactic that cynically exploits the very real and traumatic issues of police brutality and mass incarceration endured by the Black community. Discriminatory policing, excessive force, and systemic racism exist independently of public health measures and must be addressed. The FDA menthol ban would prohibit the manufacture and retail distribution of menthol cigarettes. It would not criminalize individuals for purchasing, using, or possessing menthols. The FDA menthol ban is about the source, the vector of death and disease.

While the FDA announcement is an important victory for public health, it is really only the first preliminary step in the process. The FDA says it will start the

\section{AFFILIATION}

1 Action on Smoking and Health, Washington, United States

2 Public Health Law Center, Minneapolis, United States 3 The Center for Black Health and Equity, Atlanta, United States

4 African American Tobacco Control Leadership Council, San Francisco, United States

CORRESPONDENCE TO Kelsey Romeo-Stuppy. Action on Smoking and Health, 1250 Connecticut Ave, NW, 7th floor Washington, DC 20036, United States. E-mail: Romeostuppyk@ash.org

\section{KEYWORDS}

menthol, social justice, targeted advertising

Received: 6 October 2021 Accepted: 7 October 2021 
rulemaking process, which will likely include time for the agency to receive comments from the public and other administrative steps before making a final rule. There is no known timeline for this process and the tobacco industry will use all its might and resources to lobby against it. AAATCLC, ASH, and our fellow plaintiffs, are encouraging the court to urge the FDA to expedite this potentially lengthy process, and to continue the lawsuit until the FDA has a finalized rule. It is essential that the public health community stands behind a proposed ban on menthol cigarettes in order to make progress towards health equity and social justice in the United States.

\section{REFERENCES}

1. Action on Smoking and Health. National Medical Association (NMA) Joins AATCLC, AMA and ASH in Lawsuit Against the FDA. Accessed May 28, 2021. https://ash.org/nma-joins-lawsuit-against-fda/

2. U.S. Food and Drug Administration. FDA Commits to Evidence-Based Actions Aimed at Saving Lives and Preventing Future Generations of Smokers. Accessed August 23, 2021. https://www.fda.gov/news-events/ press-announcements/fda-commits-evidence-basedactions-aimed-saving-lives-and-preventing-futuregenerations-smokers

3. Centers for Disease Control and Prevention. African Americans and Tobacco Use. Accessed April 15, 2021. https://www.cdc.gov/tobacco/disparities/africanamericans/index.htm

4. Yerger VB, Przewoznik J, Malone RE. Racialized geography, corporate activity, and health disparities: tobacco industry targeting of inner cities. J Health Care Poor Underserved. 2007;18(4 Suppl):10-38. doi:10.1353/hpu.2007.0120

5. Cision PR Newswire. National Black \& Hispanic Editors, Publishers, Law Enforcement Groups Issue Warning to the FDA: A Menthol Ban Would Increase Police Interactions in Communities of Color. Accessed October 26, 2021. https://www.prnewswire.com/ news-releases/national-black--hispanic-editorspublishers-law-enforcement-groups-issue-warningto-the-fda-a-menthol-ban-would-increase-policeinteractions-in-communities-of-color-301278585.html

\section{CONFLICTS OF INTEREST}

The authors have each completed and submitted an ICMJE form for disclosure of potential conflicts of interest. The authors declare that they have no competing interests, financial or otherwise, related to the current work. L. Huber reports that since the initial planning of the work he was employed by Action on Smoking and Health (ASH), a US based nonprofit organization dedicated to tobacco control, and that within the past 36 months ASH did receive a grant from Kaiser Permanente in 2020 to develop webinars on how to use global governance mechanisms to support menthol bans in

tobacco products to protect the health of African Americans. C. McGruder reports programmatic funding from the California Tobacco Control Program/The Center for Black Health and Equity and that she was Co-Chair of the African American Tobacco Control Leadership Council and President of the 'Protect Our Children from Flavors' campaign California, within the past 36 months. N. Phelps reports that since the initial planning of the work, was a Public Health Law Center employee funded by the Robert Wood Johnson Foundation, and within the past 36 months she was part of The Center for Black Health and Equity.

\section{FUNDING}

There was no source of funding for this research.

ETHICAL APPROVAL AND INFORMED CONSENT

Ethical approval and informed consent were not required for this study.

DATA AVAILABILITY

Data sharing is not applicable to this article as no new data were created.

PROVENANCE AND PEER REVIEW

Commissioned; internally peer reviewed. 